\title{
A teoria de Hundertwasser e sua relação com o movimento Slow fashion
}

Vanessa Mazzocchi Koppe

Mestranda, Universidade do Estado de Santa Catarina lattes

Neide Köhler Schulte

Doutora, Universidade do Estado de Santa Catarina Orcid: 0000-0001-5690-5819/ lattes

Sandra Regina Rech

Doutora, Universidade do Estado de Santa Catarina Orcid: 0000-0002-0062-6914/ lattes

Icléia Silveira

Doutora, Universidade do Estado de Santa Catarina Orcid: 0000-0003-4493-9768/ lattes 


\section{A teoria de Hundertwasser e sua relação com o movimento Slow \\ fashion}

\section{RESUMO}

Este artigo se propõe a desenvolver uma relação entre tendências de comportamento, a obra do artista Hundertwasser e o movimento Slow fashion, e compreender melhor como a moda influencia nas atitudes pessoais e de que forma ela tem contribuído para as grandes mudanças do mercado atual. Através de uma análise comportamental, demonstrar que a identidade de cada um se constrói a partir do que ele consome e seu modo de vida.

Palavras-chave: design de moda. Tendência. Hundertwasser. 


\title{
Hundertwasser's theory and its relation to the Slow fashion movement
}

\begin{abstract}
This article proposes to develop a relationship between behavioral tendencies, the work of Hundertwasser's artist and the Slow fashion movement, and understand better how fashion influences personal attitudes and how it has contributed to huge changes of the current market. Demonstrate through the behavioral analysis that each identity is built from the consumes and way of life.
\end{abstract}

Keywords: fashion design. Trend. Hundertwasser. 


\title{
La teoría de Hundertwasser y su relación con el movimiento Slow fashion
}

\begin{abstract}
O
Este artículo se propone desarrollar una relación entre tendencias de comportamiento, la obra del artista Hundertwasser y el movimiento Slow fashion, $y$ entender mejor cómo la moda influye en las actitudes personales $y$ cómo ha contribuido a los grandes cambios del mercado actual. A través de un análisis conductual, demostrar que la identidad de cada uno se construye a partir de lo que él consume y su modo de vida.
\end{abstract}

Palabras clave: diseño de moda. Tendencia. Hundertwasser. 


\section{INTRODUÇÃO}

A moda é um dos fenômenos sociais e culturais do mundo contemporâneo que mobiliza e influencia as pessoas. Sua contribuição na formação da identidade de cada indivíduo é direta, pois o sistema de moda é responsável por impulsionar tendências, conceitos e ideias. Quando se fala de tendências, há uma referência direta com moda. De modo geral, tendência é uma inclinação para algo, uma força de atração. $\mathrm{Na}$ moda tendências são previsões, especulações obtidas através de pesquisas de comportamento e consumo. Campos (2013) afirma que o estudo de tendências envolve pesquisar o presente e traçar planos, visões e conjunturas sobre o futuro.

Vivemos num mundo em que tudo e todos estão em constante mutação. Essa mudança está ligada ao novo ritmo de vida. O consumidor está cada vez mais atento a questões éticas, e as empresas que não se adaptarem podem ficar fora das demandas de consumo das novas gerações.

Segundo Berlim (2012, p. 88), "nos últimos anos a sociedade passou a entender melhor os conceitos do 'sustentável' e os criadores por sua vez, passaram a compreender que nada pode ser $100 \%$ sustentável e que qualquer prática de sustentabilidade é bem-vinda na produção de um produto". Partindo dessa premissa, o presente trabalho propõe estabelecer uma relação entre a Teoria das Cinco Peles de Hundertwasser e o movimento do Slow fashion, através de uma ótica comportamental.

Embora o consumo seja inevitável, além de ser importante para a cadeia produtiva, podermos pensar a moda através de uma ótica sustentável. Esta é uma das formas mais significativas para as mudanças no cenário da sociedade atual. A indústria da moda e vestuário gera muitos empregos 
no cenário mundial, mas por outro lado, também é uma indústria que gera muitos resíduos. O cenário da sustentabilidade abrange, não só uma evolução no processo produtivo das indústrias da moda, mas também a compreensão de um novo estilo de vida do consumidor, engajado com os problemas da humanidade e preocupado com os valores éticos, através de suas escolhas de consumo.

$\mathrm{Na}$ obra de Hundertwasser - artista austríaco conhecido por recomendar vivamente a sustentabilidade - ele defende que o consumismo distancia o homem de seus verdadeiros objetivos: o bem estar, o aproveitar bem e o fazer bem ao meio ambiente. Hundertwasser constituiu uma corrente que batizou de trans-automatismo, um tipo de surrealismo centrado na visão pessoal do observador - onde podemos identificar duas grandes tendências mundiais - a identidade e a sustentabilidade.

Restany (2003) fala que para Hundertwasser, o corpo humano é constituído por cinco peles, onde o indivíduo se cria por camadas partindo da sua derme, para a terra, lugar onde vive e as denomina da seguinte forma: A Epiderme, $O$ Vestuário, A Casa, A Identidade Social e O Meio Global e Ecológico. E esta é uma de suas teorias, tratadas neste estudo.

A escolha do tema veio através do interesse em pesquisar tendências e comportamentos, visto que cada ser humano é único e tem sua identidade, e seus gostos pessoais surgem a partir das experiências vividas. Além disso, compreender melhor como a moda influencia nas atitudes pessoais e dita estilos através da roupa é de grande importância diante das grandes mudanças do mercado atual e como Lee (2009) afirma, "[...] a sustentabilidade pode ser um bom negócio". Assim, desenvolver esse estudo para ressaltar a relevância da 
sustentabilidade na moda tem grande importância e para a sociedade.

Do ponto de vista sustentável, reunir informações e desenvolver uma análise sobre o comportamento humano, através do movimento do slow fashion, movimento ético e unificado que promove uma alternativa de redução à produção em massa, é uma forma de referenciar a moda ecológica, que vem se destacando como uma das grandes mudanças comportamentais, além de facilitar o processo de transição para a conscientização dos consumidores e de práticas sustentáveis dos designers, que precisam modificar os processos de projetação, incluindo o DNA sustentável desde o início de seus projetos.

A abordagem dessa pesquisa será qualitativa fundamentada no resgate bibliográfico, buscando-se dados informativos acerca do tema, através de uma pesquisa descritiva.

\section{TENDÊNCIA}

Através dos estudos de tendências podemos obter informações relevantes sobre o comportamento social, tornando-se assim uma ferramenta importante para identificar e analisar a evolução do consumidor e sua mentalidade. O termo tendência, segundo Caldas (2004, p. 23) provém do latim tendentia, substantivo do verbo tendere, que significa "tender para", "inclinar-se para" ou "atraído por", ou seja, é uma inclinação ou preferência por determinada coisa. Sendo assim, as tendências funcionam como uma representação de futuro, de cenários que tendem a acontecer.

Pode ser compreendida como fenômeno que se define sempre em função de um objetivo ou de uma finalidade, que exerce força de atração 
sobre aquele que sofre a tendência; ela expressa movimento e abrangência; é algo finito (no sentido de que se dirige para um fim) e, ao mesmo tempo, não é $100 \%$ certo que atinja o seu objetivo; é uma pulsão que procura satisfazer necessidades (originadas por desejos) e, finalmente, trata-se de algo que pode assumir ares parciais e pejorativos (CALDAS, 2004, p. 26).

Caldas (2004, p. 43) acredita que o conceito de tendência foi sendo construído ao longo do tempo, respondendo a um tipo de sensibilidade específica que se descortinou com a modernidade com seu culto ao novo, consagrando-se na pósmodernidade onde a liquidez comportamental se mostrou em voga.

As tendências poderiam ser descritas no âmbito sociológico, segundo Erner (2015, p. 12), como "um comportamento adotado de maneira temporária por uma parte substancial de um grupo social quando esse comportamento é percebido como socialmente adequado para a época e situação". Ainda para esse autor, a sociologia das tendências buscaria dar uma resposta para a transformação do gosto coletivo, o que nos leva a perceber que o foco das tendências está nas alterações do gosto e no entendimento de como se propagam.

No processo de identificação de tendências é essencial construir o melhor entendimento possível do espírito do tempo e do momento em que vivemos. Torna-se necessário conhecer o "Zeitgeist". Para Vejlgaard (2008), através do processo de identificação, observação e da análise podem ser retiradas pistas que ajudem na identificação de padrões de comportamento, e que levem a reconhecer manifestações de uma ou várias tendências e do seu potencial de crescimento. Com os estudos de tendências, ao observarem-se padrões de comportamentos que levam à identificação de tendências, pode ser gerada inovação que, aplicada a estratégias 
empresariais, vai ao encontro daquilo que o consumidor está recetivo, num determinado momento.

A análise de tendências pode ser considerada prospecção quando se fala em pensar o futuro. Para Vejlgaard (2008) as mudanças no estilo e no gosto têm se desenvolvido há vários séculos, e vem atingindo um ritmo exponencial nas primeiras décadas do século XXI. Para Caldas (2017) é praticamente unanime apontar o individualismo com um traço definidor do ethos no século XXI. As motivações de consumo mudaram, principalmente aquelas que dizem respeito às escolhas individuais.

A noção de bem-estar e qualidade de vida, compartilhadas pela maioria, assumiriam significados pessoais, tendo como denominador comum a percepção central dos indivíduos com os cuidados de si, ou wellness, como viria a ser conhecida essa esfera hipertrofiada do estilo de vida (CALDAS, 2017, p. 81).

Partindo da ideia de que atualmente existem diferentes processos de mudança na sociedade e que nem todas elas ocorrem da mesma maneira, muitos estudiosos e sociólogos estudam como as pessoas se adaptam a novas ideias e conhecimentos, através de novos comportamentos. A partir dessa premissa o presente artigo pretende entender o comportamento do slow fashion, através de uma leitura do estudo de Hundertwasser e a teoria das cinco peles, tema abordado no próximo tópico.

\section{O ARTISTA DAS 5 (CINCO) PELES}

Friedensreich Hundertwasser, nascido em Viena no dia 15 de Dezembro de 1928, elaborou seu trabalho fundamentado na reconstrução do modo de ver a vida. Ficou conhecido como "médico da arquitetura", por recomendar vivamente a 
sustentabilidade e por odiar a linha reta, e acreditar que a integração de elementos sustentáveis pode levar o homem atingir uma vida mais tranquila e feliz.

Em 1972 Hundertwasser publica o manifesto "O Teu Direito de Janela - O Teu Dever de Árvore" e intervém espetacularmente numa emissão de televisão a favor de um habitat de melhor qualidade: telhados cobertos de vegetação e arranjo individual das fachadas (RESTANY, 2003, p. 8).

Segundo Restany (2003), Hundertwasser defende que o consumismo distancia o homem de seus verdadeiros objetivos: o bem estar, aproveitar bem e fazer bem ao meio ambiente. Assim, construiu uma teoria na qual apoia que 0 indivíduo se cria por camadas partindo da sua derme para a terra, lugar onde vive. E a denomina de As 5 (cinco) peles do humano: A Epiderme, O Vestuário, A Casa, A Identidade Social e O Meio Global e Ecológico. A Figura 1 mostra a espiral criada por Hundertwasser.

Figura 1. A espiral de Hundertwasser. 


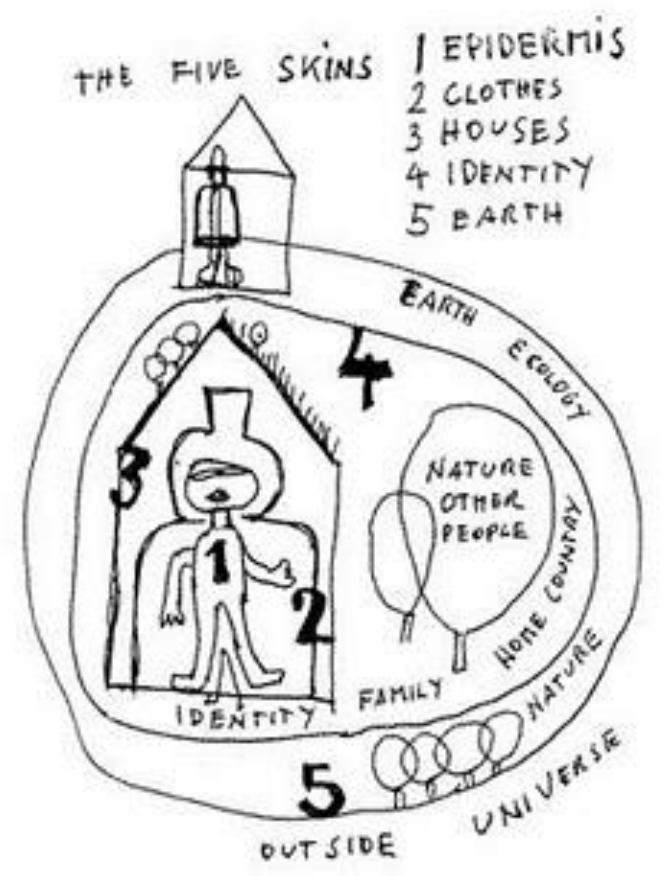

Fonte: http://opcao-criativa.blogspot.com.br/

\subsection{A primeira pele - A epiderme}

A primeira pele consiste no envolvimento do ser humano associado com a natureza e com o mundo orgânico, um regresso a princípios antecessores e formadores da condição humana, de reconhecimento de nossos sentidos, sentimentos e seus diversos significados. Para Nunes (2008), a epiderme consiste no Eu. Como capa, superfície sensível, integrante do corpo humano. A epiderme transmite as necessidades básicas do ser humano: das fisiológicas à sexualidade e à morte.

Oliveira (2008) comenta que a primeira pele é a da aprendizagem, do sentimento terreno de um corpo inteiro e sustentável, força de energia vital. O autor também afirma que Hundertwasser e o seu Eu de múltiplas peles instalam a espiral iniciada em si, e ao imaginar dessa maneira se inicia um significado de relação primeira consigo e com a dimensão terrena de nosso corpo, como um processo de descoberta de 
nossos encontros orgânicos e energéticos com a dimensão terrena da natureza.

A espiral de Hundertwasser é austríaca, Jugendstil, barroca, romana, celta, copta, mesopotâmica, maori, religiosa: eis porque nos arrasta também 'naturalmente' no sentido da perspectiva infinita dos diferentes inconscientes que ocupam a alma (RESTANY, 2003, p. 17-18).

Para Hundertwasser, o poder criativo do homem refere-se à existência de sua natureza, a sua liberdade. O homem precisa ficar nu, conforme Figura 2, aberto para a criação e livre das exigências e manipulações das pessoas.

Figura 2. Hundertwasser durante o discurso nu contra o racionalismo em arquitetura (1967)

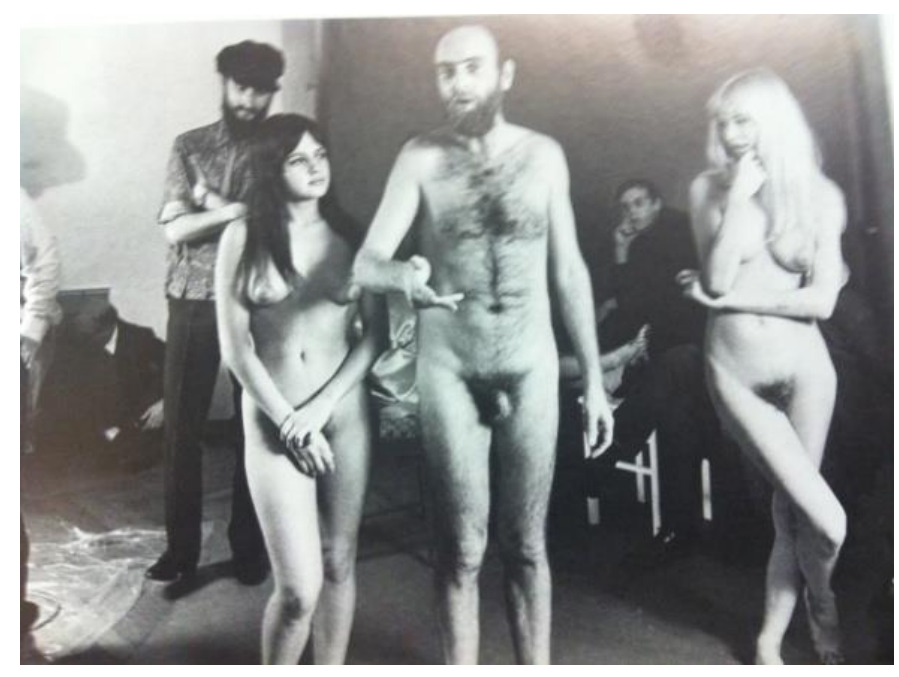

Fonte: http://www.flutuante.wordpress.com

Para o artista, mostrar sua beleza nos seus aspectos de intensidades mais sublimes é uma forma de conduzir um testemunho impulsivo e espontâneo de cada indivíduo. Segundo Restany (2003, p. 17) Hundertwasser acreditava que a graça da beleza era o segredo da criatividade no mais profundo da alma humana. 


\subsection{A segunda pele - O vestuário}

Hundertwasser confeccionava suas próprias roupas. Costurava os casacos, chapéus e sapatos. O artista começou a fazer suas roupas quando tomou consciência da sua segunda pele. Na Figura 3 pode se observar os sapatos que o próprio artista confeccionava.

Figura 3. Hundertwasser com sapatos de Inverno e Verão confeccionados por si próprio, Paris 1950.

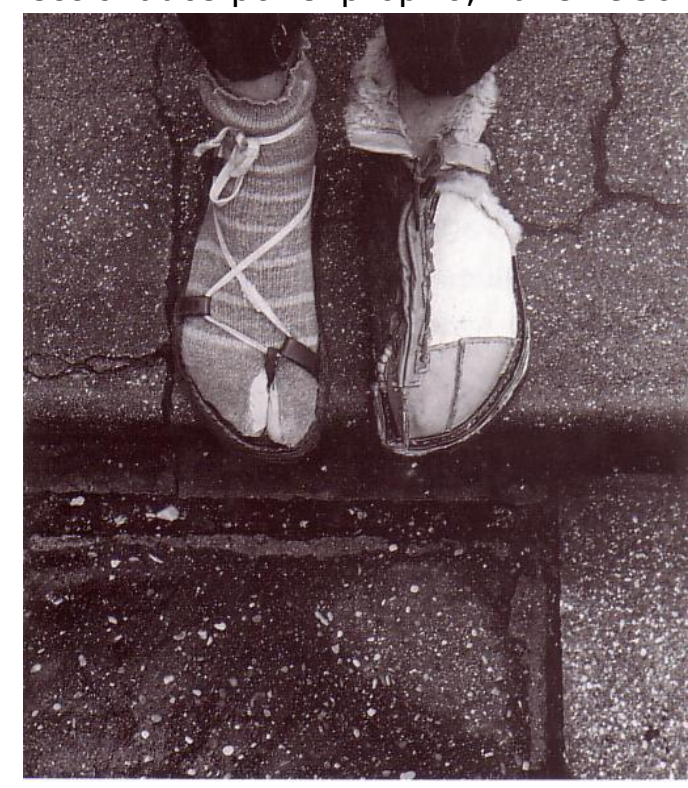

Fonte: http://brasiliaconcreta.com.br/

Mais que um simples pano revestindo o corpo, a roupa é a visibilidade do homem no mundo. Hundertwasser opõe-se a produção e a fabricação de peças em série, incentivada pela globalização e pelos costumes de consumo, pois mecanizam e igualam o homem quando deveriam atestar sua individualidade através da roupa. Neste sistema de produção, todos são atingidos por males, no que se refere a segunda pele: a uniformidade, a simetria e a tirania da moda (RESTANY, 2003).

A segunda pele é efêmera, assim como a cultura moderna, podendo facilmente modificar. A roupa, como prolongamentos 
do corpo, mostra que de um lado está a pessoa e do outro a "impressão" que ele deseja passar. Todavia, é por meio do corpo que se percebe e vivencia o universo que o rodeia. Vivese em uma sociedade onde o corpo é formado "artificialmente" e à mercê da moda. Assim, "sobre a pele de cada indivíduo, como novo conjunto de textos, a segunda pele, em suas múltiplas manifestações, permite o norteamento e a orientação que se refere à posição individual do sujeito diante do coletivo, do privado em relação ao público" (CASTILHO, 2004, p. 73).

A uniformidade do anonimato do vestuário traduz no homem a renúncia ao individualismo, ao orgulho de usar uma segunda pele criativa, original e diferente das outras (RESTANY, 2003). A roupa não mais se limita a esconder, mas sim revela a subjetividade do ser humano para o universo exterior, ao mesmo tempo em que favorece a interiorização do sujeito que dela faz uso. Ela tem uma função política, social, sociológica, ao apresentar nossa identidade individual ao mundo externo (NUNES, 2008).

Tanto em seus quadros quanto em suas roupas e na arquitetura, Hundertwasser valoriza o colorido, negando a cor cinza e a harmonia monocromática. Sua regra de beleza aplica-se a todo o universo criativo que rodeia o homem. Componente vital da beleza, ele concede ao colorido uma condição de sagrado. A segunda pele é o poder de afinidade que a roupa exerce na pessoa. Assim, ficar ou não na moda depende do "pacote" que contorna o corpo.

\subsection{A terceira pele - A casa}

A casa, o teto, as paredes, as janelas e as portas, entradas e saídas, acolhem e abrigam o humano, e sugerem a terceira 
pele. A morada do corpo imenso constrói e leva vivamente suas cores e formas no lar da vida. A casa onde o homem reside e realiza suas obrigações cotidianas, é o local erguido onde passa a maior parte das horas. Para Hundertwasser, "uma casa deve interagir diretamente com a natureza, deve ser orgânica, viva e em estado de mudança contínua" (SILVA, 2013, p. 27).

Nunes (2008) descreve que o "Direito de Janela" defende a execução da individualidade e a eficiência de invenção em nossos próprios círculos. Concede-nos a liberdade de enfeitar a fachada ao redor das janelas de nossas casas de acordo com nossos anseios e interesses pessoais. "Toda grande imagem simples revela um estado de alma. A casa, mais ainda que a paisagem, é "um estado de alma". Mesmo reproduzida em seu aspecto exterior, ela fala de uma intimidade" (BACHELARD, 1993, apud NUNES, 2008, p. 28).

O "Dever de Árvore" consiste na preocupação do relacionamento humano com a natureza. Nunes (2008) comenta a importância de que a natureza seja trazida às construções criadas pela sociedade. Hundertwasser elaborou esse projeto para lembrar a todos de que a perda de contato com a natureza acarreta desorientação à humanidade. A Figura 4 contempla o projeto árvore-locatária.

Figura 4. O projeto árvore-locatária, Via Manzoni, Milão, 1973. 


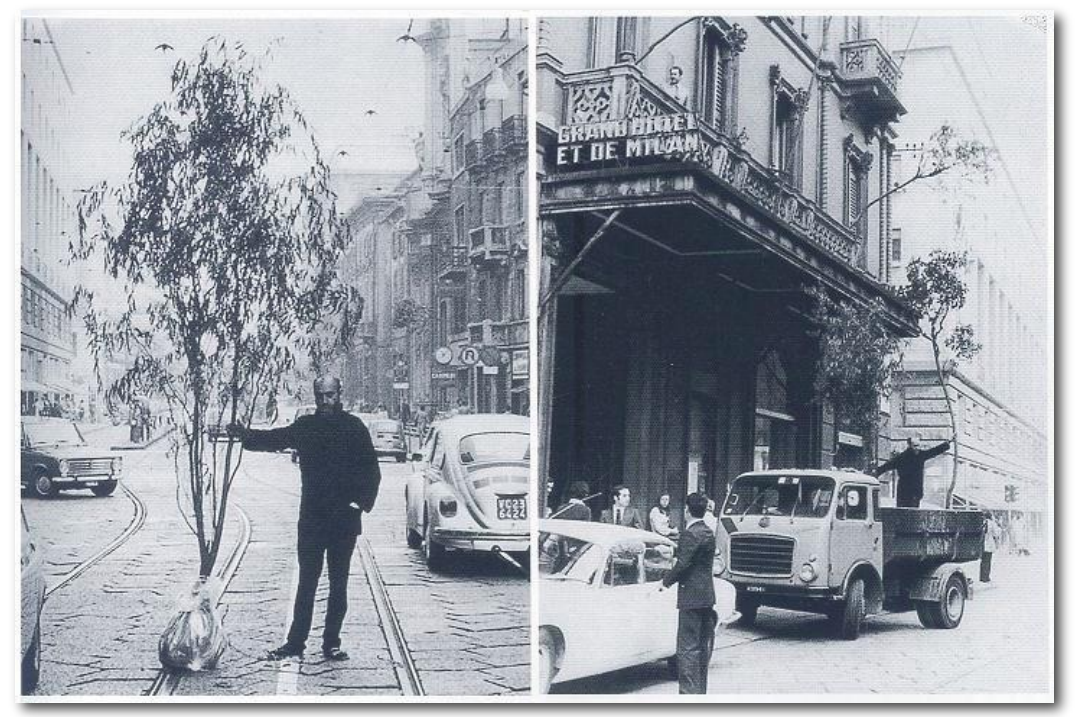

Fonte: RESTANY, 1999.

A humanidade deve, após ter exercitado sua natureza destrutiva por tanto tempo, firmar um tratado de paz com a natureza. Para o pintor quando deixamos a natureza repintar as paredes, elas tornam-se humanas e nós podemos voltar a viver.

\subsection{A quarta pele - A identidade social}

A quarta pele de Hundterwasser está relacionada diretamente com a família e com o universo socio-cultural. Sendo assim, sua quarta pele tem uma grande ligação com as questões emocionais dos objetos que interferem ou influenciam na identidade do homem usuário.

A quarta pele não cessa ao nível da família, natural ou adquirida, mas se estende ao meio social, "ao conjunto dos grupos associativos que gerem a vida de uma colectividade" (RESTANY, 2003, p. 65). Conforme Nunes (2008, p. 42) "Hundertwasser tem simpatia pela identidade doada por uma nação ao seu povo". A quarta pele, ou seja, o meio social se 
organiza no conjunto de grupos associativos que fornecem vida a um coletivo.

Nunes (2008) também mostra que para obter a harmonia universal, o artista defende a proposta de sociedade estéticonaturista pacifista. Ou seja, crê que a beleza projeta a paz; de forma que o cidadão de "espaços felizes", ofertados por sua arquitetura natural, goza de felicidade com todos que convive. O mesmo constata a força nacional em relação aos cidadãos e dedica-se a distinguir e afirmar a identidade de um povo: a bandeira, selos postais, entre outros símbolos que os identifique como nação.

A marca mais móvel da identidade nacional criada por Hundertwasser "constitui-se em seu código de prática moral: as imagens representadas são repletas de beleza e transmitem paz" (NUNES, 2008, p. 44). O artista coloca em prática sua imaginação na criação de moedas, porém, sem valor comercial reconhecido. Além das moedas, produz também uma série de relógios "Time drops" e relógios de pulso, formas de cartões telefônicos e fichas de cassino.

Restany (2003), ao relatar a Teoria das 5 (cinco) peles do humano, classifica o artista como um homem amoroso, ao julgá-lo um "pintor" de um quadro para viver sempre melhor. "Viver sempre melhor" seria sua quinta e última pele - ligado à humanidade, a natureza e o meio ambiente.

\subsection{A quinta pele - O meio global - ecologia e humanidade}

Para Hundertwasser pertencemos todos a uma grande teia de conhecimentos e práticas de outras formas de agir e viver. Oliveira (2012) afirma que na lógica Hundertwasseriana todos os praticantes passam a compartilhar de uma mesma pele, transferindo fundamentos para um repensar de seus limites. 
Seu modo de viver passa a se confrontar com a ditadura da razão e da simetria, pois, agora, se cresce disforme e irregular para todos os lados, seguindo o fluxo, do acontecer, da criatividade, redesenhando assim o ambiente e o integrando como última morada.

Para o artista a natureza é fonte máxima da harmonia humana. Seu parecer de santidade da natureza recebe apoio nas resoluções de proteção contra o desgaste realizado pelo homem e pela indústria. Nunes (2008) considera que a intervenção da ordem superior da natureza na sua restruturação voluntária destaca-se no corpus teórico do artista a partir da negação da linha reta, em 1953, sempre seguido de um plano viável.

A etapa essencial da casa eco-naturista criada por Hundertwasser possui cobertura de grama reforçada pelo húmus do sanitário e como as árvores-locatárias das janelas. Essas plantas armazenam a água da chuva para utilização na casa. A purificação das águas de esgoto é executada por plantas de filtragem. A Figura 5 destaca uma cerimônia realizada para a plantação de árvores.

Figura 5. Cerimônia de plantação de árvores, Judiary Square, Washington, 18 de novembro. 


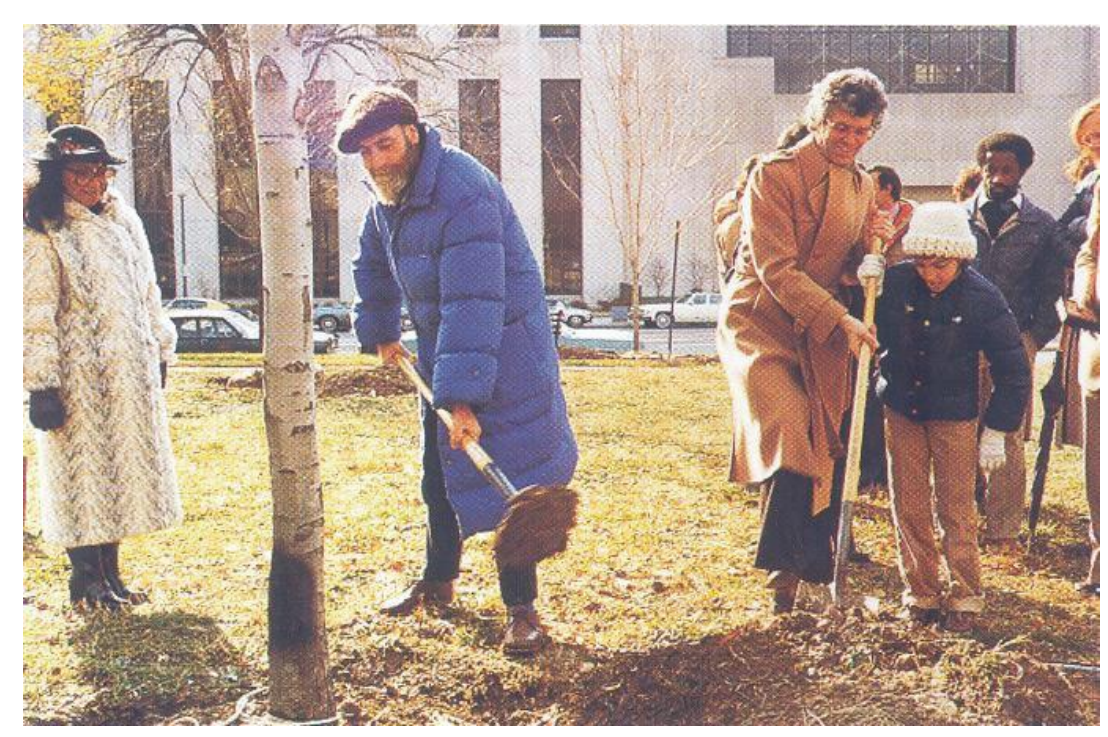

Fonte: RESTANY, 1999.

Esta cerimônia realizada para a plantação de árvores simboliza a preocupação com as ameaças contínuas à natureza, os malefícios da força nuclear, que levaram Hundertwasser explorar a selva amazônica.

Restany (2003) afirma que Hundetwasser conhece a exata natureza carismática dos conceitos de suas polêmicas e que seu talento mede-se pelo poder de impacto dessas ideias sobre a sustentabilidade estética das consciências individuais. Através de um olhar que reside na persistência retiniana da memória perspectiva e na indestrutível força espiritual do olhar luminoso sobre o mundo que o autor nos convida a pensar na moda como uma possibilidade de consciência comportamental, assunto que será tratado no próximo tópico através de um breve entendimento do slow fashion.

\section{SLOW FASHION}


De acordo com Fletcher e Grose (2011) o cerne da sustentabilidade está centrado na experiência da conexidade das coisas, na compreensão vivenciada das incontáveis interrelações que vinculam os sistemas econômicos, materiais e socioculturais à natureza. Para as autoras essas conexões operam em diferentes escalas e com diferentes esferas de influências, algumas com nível local e direto, outras globalmente.

O conceito de sustentabilidade aplicado ao vestuário é recente na história da moda. Ele vem evoluindo e conforme teóricos como, por exemplo, Lipovestky (1989), desde o surgimento da moda no começo do século $X V$, ela vem acompanhando as transformações da vida das pessoas, podendo compará-la com o espírito do tempo Zeitgeist.

Para Berlim (2012), a sustentabilidade está presente na moda desde a década de 60, quando surgiram no Brasil e no mundo as primeiras preocupações com o impacto ambiental causado pela indústria têxtil. Já para Barros (2016) a noção desse termo começa a ser discutida nos anos 70, junto com as discussões sobre o meio ambiente, e em meados dos anos 80 é que os problemas relativos à pobreza e à desigualdade social são incorporados à questão ambiental.

No entanto, consumir faz parte de nossas vidas, para Lee (2009) a experiência da compra é divertida e recompensadora, ainda mais se encontrarmos algo macio, bonito, na moda e barato. Todavia, como consumidores, somos apenas uma parte dessa cadeia, pois do outro lado há inúmeras pessoas que participaram do processo de construção desse produto. Tornar-se um consumidor consciente não quer dizer deixar de consumir, mas sim equilibrar a qualidade e quantidade que se consome, pensamento esse que vai ao encontro com o surgimento do movimento slow fashion. 
O slow fashion é definido como um movimento que não responde à rapidez das mudanças das tendências da moda (WATSON; YAN, 2013). Muito se discute sobre sua definição e muitos autores apontam que o slow fashion é uma corrente que fortalece a conexão do consumidor com a roupa e os seus designers incluindo também os valores de comunidade e diversidade. Sendo assim, podemos afirmar que tratar-se de um movimento que valoriza o esmero, a qualidade e o pensamento em longo prazo.

Inspirado no slow food que tem o propósito de incentivar as pessoas a voltarem a consumir comidas de sua região sem a pressa dia a dia do mundo globalizado, o slow fashion surgiu segundo a inglesa Kate Fletcher, consultora e professora de design sustentável do britânico Centre for Sustainable Fashion, com o intuito de estimular as pessoas para que comecem a pensar nos produtos de vestuário que consumimos e o que está por trás dele em toda a cadeia produtiva em que se encontra, fazendo as pessoas refletirem sobre a maneira que eles são produzidos e valorizando a diversidade das tradições e culturas tão ricas espalhadas pelo mundo.

Como afirma Lee (2009) podemos dizer que o slow fashion deixou de ser apenas uma mera tendência e passou a ser um movimento, ele engloba questões que estão se fixando cada vez mais em nossa forma de consumo e por essa razão passou a se tornar uma nova direção do mercado de consumo da moda. O slow surgiu para conscientizar as pessoas do quão importante é consumir do jeito correto.

O movimento slow fashion sugere então uma ruptura com os valores e objetivos que são baseados apenas no crescimento econômico da indústria do vestuário, incentivando um modo de consumo onde menos é mais - a qualidade sobre quantidade - além de resgatar o valor das 
roupas retirando a imagem da moda como algo descartável, para promover uma consciência de compra que deve ser baseada na durabilidade das peças e na forma como são produzidas (POOKULANGARA; SHEPHARD, 2013).

O slow fashion está transformando também a forma como as roupas são pensadas, a forma como as pessoas as vestem e a relação entre o indivíduo e seu estilo. Um dos pilares do slow é justamente a diversificação de estilos, estimular as pessoas que criam os produtos a sempre inovar e aos consumidores terem seu próprio estilo, vestirem roupas que digam algo sobre sua personalidade, algo que realmente gostam e não algo copiado de uma marca importante feita com produtos que não respeitam a ética e sustentabilidade ou mesmo seguir as tendências que são lançadas diariamente pela indústria do fast.

Ao contrário do movimento fast fashion, o slow fashion estimula a criatividade dos designers encorajando-os sempre a inovar, desenvolver produtos inovadores que colaborem para a crescente demanda de produtos com tecnologia e personalidade que ao em vez de copiar grandes grifes utilizando materiais de baixa qualidade, busca o novo, o inusitado e o sustentável.

O slow fashion é justamente a junção que precisamos entre sustentável e ético para encontrar o equilíbrio do consumo. Ele não mostra apenas alternativas viáveis para a diminuição do impacto no meio ambiente pelos produtos e maneiras de produzi-lo, tratando inclusive da qualidade do material, a durabilidade e o preço justo pago por ele como também aborda a valorização do ser humano e seu trabalho, além de incentivar a criatividade e o estilo próprio.

Como Livni (2012) diz que a expressão slow fashion "moda lenta" não deve ser encarada como uma maneira não rentável de negócio, mas sim como uma forma de aprimorar a 
produtividade. Ela ainda ressalta que o slow não deve ser baseado em lucro na hora da venda, pelo contrário, os ganhos sociais e ecológicos que geram esses novos conceitos de produção de moda pensando em longo prazo. Essa nova forma de fazer moda une a criatividade, o artesanal e a tecnologia, com essa junção é possível criar um produto inovador, sustentável e atemporal.

Fletcher e Grose (2011) destacam o surgimento de uma nova direção da indústria da moda, onde a preocupação com sustentabilidade e com o desaceleramento do consumo, estão cada vez mais presentes. Para as autoras o processo de sustentabilidade impele a indústria da moda a mudar [...]; mudar a escala e a velocidade de suas estruturas de sustentação e incutir nestas, um senso de interconectividade.

\section{A RELAÇÃO ENTRE AS 5 (CINCO) PELES DO HUMANO E O MOVIMENTO SLOW FASHION ATRAVÉS DE UMA ÓTICA COMPORTAMENTAL}

A moda molda e é moldada por cada uma das peles do ser humano de acordo com a cultura, o local e a sociedade de cada época. O ser humano transforma cada uma de suas peles num meio de se comunicar com a sociedade a sua volta, buscando sempre a melhor e mais perfeita aparência para cada uma delas (LOBO, 2012).

A partir da dinâmica de disseminação da macrotendência do slow fashion o mapeamento de informações e dados às peles do humano passa a ser o processo principal. Para obtermos uma melhor visão sobre o processo de mudanças, nós, em todos os casos, temos que começar com o conteúdo básico dos problemas sociais. Nesse projeto pode ser verificado através das mudanças de consumo da nova geração que vem impulsionando o movimento do slow fashion como 
uma das alternativas do novo sistema moda, estimulando a diversidade ecológica, social e cultural.

A busca por uma sociedade melhor, onde o bem estar e o desenvolvimento se fazem presentes no dia-a-dia já uma realidade, pois vivemos num momento onde o consumidor busca um consumo mais "correto". Vivemos hoje uma fase do consumo em que se afirma a exigência do consumidor responsável e cidadão. É a partir dessas novas preocupações, de novos valores que as marcas já estão redirecionando seu trabalho, desenvolvendo novos produtos.

Partindo desse ponto e analisando a visão de Hundertwasser e a sua obra, podemos através das novas tendências de comportamento e de consumo identificar uma relação com o movimento slow fashion, onde conseguimos identificar em cada pele analisada a utilização de produtos característicos do movimento, com foco mais específico na quinta e última pele. Através disso foi desenvolvido o esquema relacional abaixo.

A epiderme - o ser humano modifica o seu corpo impulsionado pelas transformações sociais e culturais. Nessa pele podemos fazer uma relação direta com o slow fashion através da análise do aumento de marcas de maquiagens e cosméticos orgânicos, onde o consumidor passou a se preocupar consigo e com o que usa na sua pele, trazendo isso para o contexto social. Tatuagens com símbolos orgânicos e naturais também podem ser uma demonstração da leitura da tendência na primeira pele. Fazendo uma relação direta com o pensamento do artista.

O vestuário - o vestuário, como extensão do corpo, mostra que de um lado está o indivíduo e de outro o "papel" que ele pretende interpretar. Vestir-se está relacionado à facilidade de o ser humano trocar de pele. Aqui podemos analisar o crescimento e desenvolvimento de marcas autorais, 
bem como o lançamento de marcas veganas no mercado. Muitos consumidores têm buscando por novas e mais duradouras formas de consumir.

A casa - a moradia de cada ser humano é influenciada constantemente com suas características pessoais. A casa de cada indivíduo não deixa de ser uma extensão do corpo, e podemos ver um crescimento no mercado onde a arquitetura e o design se uniram para desenvolver projetos e decoração sustentáveis, além de novas alternativas de slow como desenvolvimento de hortas orgânicas em casas e condomínios.

A identidade social - A quarta pele tem uma grande ligação com as questões emocionais dos objetos e elementos que interferem ou influenciam na identidade do homem usuário. Hundertwasser distingue e afirma a identidade de um povo através de seus símbolos que o identifique como nação. Podemos relacionar aqui o estilo de vida, hábitos e costumes e toda a simbologia que identifica esta tendência. Essa busca por espaços wellness, spas híbridos, atividades ao ar livre, entre outros.

O meio global e o slow fashion - está relacionado com a sustentabilidade, em viver em harmonia com o ambiente. É ter uma consciência ecológica, grande tendência mundial. A quinta e última pele é que mais se relaciona com o movimento slow fashion, e na qual fortalecemos a relação entre a teoria de Hunterwasser com sua contribuição para o Design de Moda. Nela conseguimos englobar todas as outras peles, e mostrar que o comportamento se dá através de tudo que o indivíduo consume e seu modo de vida.

\section{CONCLUSÃO}


Este trabalho teve como objetivo relacionar a Teoria das 5 peles de Hundertwasser, à sustentabilidade e o movimento slow fashion. Pode-se observar que a teoria Hundertwasser contribui no entendimento de como se dá a relação do indivíduo com o seu entorno, desde o seu próprio corpo até o planeta como um todo.

O movimento do slow fashion se relaciona diretamente com a teoria de Hundertwasser principalmente a partir da análise da quinta pele onde se observa uma grande tendência comportamental na busca pela consciência ecológica integral, fortalecendo a ideia de evolução do design de moda para um consumo mais consciente.

A partir desse artigo, novos estudos sobre a temática serão desenvolvidos na busca de um referencial comportamental para as novas gerações, através da leitura do movimento slow fashion e sua contribuição para a construção de um novo sistema de moda, com uma visão sustentável e com práticas conscientes de produção e consumo.

\section{REFERÊNCIAS}

BERLIM, Lilyan. Moda e Sustentabilidade: uma reflexão necessária. São Paulo: Estação das Letras e Cores Editora, 2012.

CALDAS, Dario. Observatório de Sinais: teoria e prática da pesquisa de tendências. Rio de Janeiro: Senac Rio, 2004.

CALDAS, Dario. Vestígios do Futuro: estilos de vida, consumo e tendência. 1. Ed São Paulo, 2017.

CASTILHO, Káthia. Moda e Linguagem. São Paulo: Anhembi Morumbi, 2004.

ERNER, Guillaume. Sociologia das Tendências. Coleção GGmoda, 2015.

FLETCHER, Kate; GROSE, Lynda. Moda \& Sustentabilidade: design para mudança. São Paulo: Editora Senac São Paulo, 2011.

LEE, Matilda. ECO CHIC: O guia de moda ética para a consumidora consciente. 1.ed.São Paulo: Larousse, 2009.

LIPOVETSKY, Gilles. O império do efêmero: a moda e seu destino nas sociedades modernas. São Paulo: Companhia das Letras, 1989. 
LOBO, Suelem Costa. A moda na construção das 5 (cinco) peles do ser humano. São José, 2012. Disponível em: https://prezi.com/z3k2uj0hu3gc/a-moda-na-construcao-das-5cinco-peles-do-ser-humano/. Acesso em: 26 jun. 2015.

NUNES, Katia. Hundertwasser: Arte e Ecologia. Trabalho de Conclusão do Curso de Licenciatura e Artes Plásticas da Universidade do Estado de Santa Catarina. Florianópolis, 2008.

OLIVEIRA, Marcio Romeu Ribas de. \#Hunderwassercorpoimensoeducador. PPGE/ME FURB. Agosto, 2008.

POOKULANGARA, Sanjukta; SHEPHARD, Arlesa. Slow fashion movement: understanding consumer perceptions - na exploratory study. Journal of retailing and consumer services. EUA: v. 20, n. 2, p. 200-206, janeiro 2013.

RESTANY, Pierre. O Poder da Arte Hundertwasser - O Pintor-rei das Cinco Peles. Koln: Taschen, 1999.

SILVA, Eric da Costa. Das cores e das peles - A construção de uma identidade múltipla. Brasília, 2013.

VEJGAARD, H. Anatomy of a trend. Nee York: McGraw-Hill, 2008.

WATSON, Maegan; YAN, Ruoh-Nan. An exploratory study of the decision processes of fast versus slow fashion consumers. Jornal of fashion marketing and management. EUA: v.17, n. 2, p. 141159, setembro 2013. 